PREDISPOSING FACTORS AND CONSEQUENCES

OF OCCUPATIONAL STATUS FOR LONG-TERM UNEMPLOYED YOUTH:

A LONGITUDINAL EXAMINATION

Author:

Peter A. Creed

School of Applied Psychology

Griffith University

Contact Address:

Dr Peter Creed

School of Applied Psychology

Griffith University

PMB 50 Gold Coast Mail Centre

Queensland, Australia 4217

Telephone: 0755948810

Facsimile: 0755948291

E-mail: p.creed@bhm.gu.edu.au 


\title{
PREDISPOSING FACTORS AND CONSEQUENCES \\ OF OCCUPATIONAL STATUS FOR LONG-TERM UNEMPLOYED YOUTH: \\ A LONGITUDINAL EXAMINATION
}

\begin{abstract}
In a longitudinal study, long-term unemployed youth were assessed at T1 on measures of psychological health (self-esteem and psychological distress), general ability, and literacy levels. At T2, three occupational groups were established (those employed at T2, those continuously unemployed between T1-T2, and those unemployed at T2 who had been in the paid work force between T1-T2). These three groups were examined, firstly, in relation to predisposing factors for occupational status, and, secondly, in relation to psychological health consequences of occupational status. Psychological health was not identified as a predictor of occupational status. Reductions in psychological distress occurred at T2 for the employed group only. No changes occurred in self-esteem for any group. General ability, literacy levels, and length of unemployment were identified as predisposing factors for occupational status. Those with higher general ability, better literacy and shorter periods of unemployment at $\mathrm{T} 1$ were more likely to be employed at T2.
\end{abstract}

Key words: unemployed youth, general ability, psychological distress, self-esteem, general ability 
Large numbers of people across many countries continue to be affected by unemployment. In Australia, the official unemployment rate hovers between 8-9 per cent (ABS, 1997a). This equates to some 800,000 people out of work, with approximately one third of these being out of work for 12 months or more (ABS, 1997b). Estimates that there are large numbers of "hidden unemployed" who do not feature in official statistics place this figure much higher (Sheehan, 1980). The evidence for young people (aged 15-24 years) is that they are disproportionately more disadvantaged by unemployment. During the 1980s and 1990s youth unemployment rates have been substantially higher than the general rate, and are currently nearly double that for adults (ABS, 1997c). Some youth segments, (e.g., indigenous Australians, youth in heavy industrial centres) do even more poorly (ABS, 1991; ABS, 1997d).

It is well documented that for many the experience of unemployment has negative psychological well-being consequences. Evidence for this comes from very early studies carried out during the Great Depression of the 1930s (e.g., Jahoda, Lazarsfeld \& Zeisel, 1933), and from research conducted more recently (for a recent review see Winefield, 1995). Longitudinal studies have also been able to demonstrate that these negative effects have been caused by people moving from being employed to being unemployed, and are by and large not associated with individuals with fewer skills or personal resources "drifting" into joblessness (e.g., Patton \& Noller, 1990; Winefield \& Tiggemann, 1990). There is some evidence that the negative effects are ameliorated once the individual returns to work, which adds further to the argument that unemployment is the causative agent (Layton, 1986; Winefield \& Tiggemann, 1990).

Several studies have identified that unemployed youth do not suffer poorer psychological health to the same extent as older unemployed people (Rowley \& Feather, 1987; Broomhall \& Winefield, 1990). Explanations for this include youth having better financial and social 
support, and being able to see joblessness as a more legitimate status. Nonetheless, unemployed youth have been demonstrated to have poorer psychological health than youth in employment. A large scale Australian study (Morrell et al., 1994) based on the Australian Longitudinal Survey, found unemployed youth (15-24 years) to have higher levels of psychological distress (as measured by the 12-item General Health Questionnaire [GHQ12], Goldberg, 1972) than employed counterparts. Earlier studies are consistent with these findings in relation to psychological distress. Banks and Ullah (1988), summarising a large scale UK research project focusing on youth unemployment, reported consistent differences between employed and unemployed youth on distress as measured by the GHQ-12. Moreover, their conclusion was that the onset of the psychological distress occurred following the young person's unemployment. Schaufeli (1997) demonstrated that young unemployed differed on the GHQ-12 from employed (and student) groups, despite there being no differences among the groups prior to them leaving school.

The situation in relation to self-esteem is more complex. Some studies have identified clear differences between unemployed and employed youth on the dimension of self-esteem (Donovan \& Oddy, 1982; Winefield, Tiggemann, Winefield, \& Goldney, 1991), and decreases in self-esteem related to length of unemployment (Winefield \& Tiggemann, 1985). However, some longitudinal studies tracking young people out of school have reported increases in self-esteem in those who become employed, but no change (improvement nor deterioration) for those who remain unemployed (Winefield, Tiggemann, Winefield, 1991). One study (Patton \& Noller, 1984), identified an adverse impact on selfesteem in school leavers as a result of not gaining employment; while Gurney (1980) found increased self-esteem for all school leavers, but a greater increase for those who became employed. It is likely that it is the quality of the post-school occupational experience that influences development (as represented by increases in self-esteem), with those gaining 
meaningful work afforded the opportunity for optimum personal growth (see Winefield et al., 1993). Other explanations for the confusion over the findings related to self-esteem and unemployment are likely to relate to the definitions of youth (Mean Patterson, 1997), which have included those as young as 15 up to 24 years. For example, younger groups have been reported to be more susceptible to deterioration in self-esteem as a function of unemployment, than older youth (Shamir, 1986; Winefield, Tiggemann \& Winefield, 1991). Despite this evidence, there appears to be a clear difference between those youth who leave school and find satisfactory employment and those who do not.

The evidence is that when individuals become unemployed or fail to find work following school their psychological well-being is compromised. Poor psychological health, or other personal attributes (such as personality or ability) might still play a role in ensuring the person continues as unemployed. Winefield and Tiggemann (1985), for example, identified that low self-esteem and elevated depression levels were, on the one hand, caused by young people becoming unemployed after leaving school, and on the other, an antecedent to their unemployment. In this case, poor psychological health predisposed young people to unemployment.

Much of the literature investigating the negative effects of unemployment has given attention to examining a large number of individual (e.g., personality) and situational variables (e.g., financial status) that act to moderate the individual's reaction to unemployment and influence his or her capacity to cope with it. General intellectual ability has been examined as a moderating variable for susceptibility and for the experience of unemployment (Banks, Jackson, Stafford \& Warr, 1980; Layton, 1985); and has been implicated indirectly in determining employment status (Lynn, Hampson \& Magee, 1984). However, this research has not identified clear associations. It is well accepted that those more likely to be at risk of unemployment, be more likely to lose the work they have, and be 
more susceptible to intermittent periods only in the labour force, are those individuals who have lower levels of education and fewer skills (Machin, 1989). Moreover, one study, that used standardised tools to measure general ability, has identified differences between unemployed and normative samples on this dimension (Creed \& Wiener, 1998). Similar differences have also been identified when acquired skills, such as literacy and numeracy (ABS, 1997e), have been examined.

The current labour market, of course, does not simply consist of those fully employed and those unemployed. Rather, there is a variety of employment arrangements, both ongoing and intermittent. While it has been demonstrated that youths with jobs by and large have better psychological well-being than those without, it is still to be determined whether improved psychological health comes only with full-time employment, or whether having access to some paid employment is beneficial. There have been few studies examining the impact of differential occupational engagement with young people. One recent longitudinal study of school leavers (Prause \& Dooley, 1997), demonstrated that both unemployment and underemployment (including intermittent and involuntary part-time employment) had tended to retard the development of self-esteem in young people compared to their satisfactorily employed counterparts.

The present longitudinal study addresses a number of the above issues. Firstly, it examines the psychological health of a group of young Australians who were all unemployed (at T1). Secondly, the original cohort of unemployed youth are allocated (selfselected) to one of three groups at T2, (i) those employed, (ii) those unemployed with no intervening T1-T2 employment, and (iii) those unemployed with substantial intervening T1T2 employment. Psychological health of the three groups are then examined in relation to the effects of their occupational status, and in relation to the impact of their initial psychological well-being. Thirdly, the effects of general ability and core skills of literacy 
and numeracy are examined to determine the influence of these variables on occupational outcomes. Lastly, whereas previous studies have contrasted unemployed youth with employed youth, this study examines the effects of paid work involvement, as well as contrasting well-being outcomes for employed and unemployed.

\section{Method}

\section{Participants}

Participants for the study were 169 unemployed young people who were registered for work with the national employment agency in Brisbane, Australia. The group comprised 83 males $(49 \%)$ and 86 females $(51 \%)$, whose average age was 19.07 years $(S D=.92$, Range 16.8-20.9), and average length of unemployment was $13.14 \operatorname{months}(S D=11.85$, Range 0 98). Twenty-nine participants (18\%) had completed less than 10 years of schooling, 58 (35\%) had completed 10 years, $20(12 \%)$ had completed 11 years, and $58(34 \%)$ had completed 12 years.

\section{Instruments}

Psychological Well-being: The 12-item version of the General Health Questionnaire (GHQ) (Goldberg, 1972) was used to measure psychological distress. The 12-item version has been recommended by Banks et al., (1980) for use in occupational studies, and has been used extensively by researchers in this area (e.g., Bond \& Feather, 1988; Warr, 1987). The GHQ asked subjects to report on how they felt recently on a range of variables, including cognitive processing, self esteem, anxiety and depression (e.g., "Have you recently been 
able to concentrate on whatever you're doing?"). Responses were scored on a four point scale from zero to three using anchors such as "better than usual/same as usual/less than usual/much more than usual". Scores were totalled to produce global ratings with a range of 0-36. Higher scores indicated more psychological distress.

Self-esteem: The 10-item Rosenberg Self-Esteem Scale (RSE) (Rosenberg, 1965) was used to provide a measure of global evaluation of self worth (e.g., "I feel that I have a number of good qualities"). Participants were asked to respond by rating how strongly they agreed with each statement, using anchors of "strongly agree-strongly disagree". Answers were scored from 1-4 (Range $=10-40)$, with higher scores indicating higher self esteem. The RSE has also been used widely in occupational studies (Feather \& Bond, 1983; Rowley \& Feather, 1987).

General ability: The 10-minute timed version of the Standard Progressive Matrices (SPM) (de Lemos, 1989), was used to obtain an estimate of general ability. The SPM provides a measure of fluid intelligence that is substantially independent of cultural and educational experiences. The test loads heavily on Spearman's (1927) " $g$ " factor and is acknowledged as a very good "pure" measure of this construct (Jensen, 1980). The SPM has been used extensively in clinical, educational and research settings. Development, reliability and validity data are provided by de Lemos. Total raw scores are reported in this study.

Literacy: The Australian Council of Educational Research (ACER) Word Knowledge Test (WK) (de Lemos, 1990) was used to gain a measure of reading ability. The 72-item WK Test provides a measure of vocabulary acquisition and general reasoning ability, and is considered to be substantially dependent on cultural and educational experiences. WK can be used as a screening test where a rapid measure of verbal skills is required, and has been widely used in occupational selection (de Lemos). Development, reliability and validity data are provided in the manual. Total raw scores are reported. 
Numeracy: The Level 2 Arithmetic sub-test of the Wide Range Achievement TestRevised (WRAT-R) (Jastak \& Wilkinson, 1984) was used to gain a measure of mathematical ability. The 56-item WRAT-R provides convenient tools for the measurement of a number of basic academic skills (e.g., reading, spelling, arithmetic), and has been widely used to complement tests of general ability across a number of settings. Development, reliability and validity data are provided in the manual. Total raw scores are reported.

Employment Status: At T2, participants were asked to indicate and give details of (i) their current employment status, and (ii) any paid employment between T1 and T2.

\section{Procedure}

At T1, participants were surveyed for psychological well-being (psychological distress and self-esteem), and completed standardised tests of general ability, literacy and numeracy. At $\mathrm{T} 2$, four months after $\mathrm{T} 1$, questionnaires were posted to all participants. This questionnaire contained the same surveys on psychological well-being that were administered at $\mathrm{T} 1$, along with a series of questions related to participants' current and intervening occupational activities. Eighty-nine (53\%) of the 169 original participants responded at $\mathrm{T} 2$.

The 89 participants who completed both T1-T2 questionnaires were allocated to one of three groups based on occupational status at T2 and on their T1-T2 employment activities. Group "UE" were 38 participants who were unemployed at T2, and who had not worked between $\mathrm{T} 1$ and T2. This group had had no work experiences over the period of the study. Group "UE+WK" were 36 participants who were also unemployed at T2, but who had had substantial ( $>1$ week full-time) paid employment between $\mathrm{T} 1$ and $\mathrm{T} 2$. This group were 
recent participants in the labour force, but were not currently employed. Group "EMP" were 15 participants who were employed at $\mathrm{T} 2$.

\section{Results}

Subject Attrition

Little subject attrition bias was identified. Those who dropped out of the study after T1 did not differ from those who remained on any variable (age, sex, education, length of unemployment, literacy, numeracy), apart from general ability, $F(1,165)=4.73, p<.05$, with the group dropping out recording higher ability $(M=34.84, S D=8.05)$ than those who remained in the study $(M=32.13, S D=8.04)$. Summary data are presented in Table 1 .

Table 1

Summary Statistics for Participants and Dropouts at T1

\begin{tabular}{|c|c|c|c|c|c|c|c|c|c|}
\hline & \multicolumn{3}{|c|}{ Participants } & \multicolumn{3}{|c|}{ Dropouts } & \multicolumn{3}{|c|}{ Total } \\
\hline & $n$ & $M$ & $S D$ & $n$ & $M$ & $S D$ & $n$ & $M$ & $S D$ \\
\hline Age & 89 & 19.13 & .94 & 79 & 19.01 & .90 & 168 & 19.07 & .91 \\
\hline UE & 70 & 13.64 & 10.98 & 69 & 12.64 & 12.74 & 139 & 13.14 & 11.85 \\
\hline SPM & 88 & 32.13 & 8.04 & 79 & 34.84 & 8.05 & 167 & 33.41 & 8.13 \\
\hline LIT & 88 & 37.31 & 14.09 & 79 & 39.72 & 13.65 & 167 & 38.45 & 13.90 \\
\hline NUM & 88 & 26.91 & 7.09 & 79 & 25.48 & 5.86 & 167 & 26.23 & 6.56 \\
\hline GHQ & 89 & 12.04 & 4.81 & 78 & 12.32 & 5.16 & 167 & 12.17 & 4.96 \\
\hline RSE & 88 & 28.77 & 5.17 & 78 & 29.31 & 4.66 & 166 & 29.02 & 4.93 \\
\hline
\end{tabular}




\section{Gender Differences}

No sex differences were identified on any of the variables (age, education level, length of unemployment, general ability, literacy, numeracy, psychological distress, self-esteem) at T1 nor at T2 when the total group was examined. Sex differences did emerge for one of the sub-groups (Group UE). For this cohort at T1, female participants reported more psychological distress $(M=13.67$ vs. $M=9.71)$ and lower self-esteem $(M=26.6$ vs. $M=$ 29.5) than males, $t(30)=2.78, p<.01$. At $\mathrm{T} 2$, female participants remained more distressed $(M=16.53$ vs. $M=9.76)$ and had lower self-esteem $(M=26.27$ vs. $M=30.06), t(30)=$ 3.17, $p<.01$. Neither females nor males in this cohort reported significant changes in psychological distress or self-esteem from T1-T2, $p>.05$.

Intercorrelations Among All Variables at T1

Table 2 presents Pearson Product-Moment correlations for all subjects $(n=169)$ at T1, to enable an exploration of the relationships among the variables. As would be expected, strong significant positive inter-correlations were found among general ability, level of literacy and level of numeracy. Also expectedly, a strong significant negative correlation was found between psychological distress (GHQ) and self-esteem. Self-esteem was also significantly correlated with literacy, with high self-esteem being associated with higher levels of literacy. Lastly, age was significantly correlated with self-esteem, and with length of unemployment, with being older being associated with higher self-esteem and being unemployed longer. 
Table 2

Pearson Product-Moment Correlations, for all Subjects Combined, 2-tail Significance, for Variables using T1 Data; $n=169$.

Variable

Variable

12

3

5

6

7

$\begin{array}{llllllll}1 . & .25^{* *} & .09 & .14 & .13 & -.07 & .18^{*} \\ (\mathrm{n}=139) & (\mathrm{n}=167) & (\mathrm{n}=167) & (\mathrm{n}=167) & (\mathrm{n}=167) & (\mathrm{n}=166)\end{array}$

2. UE

$\begin{array}{llllll}.09 & -.01 & .09 & -.02 & .06\end{array}$

$(\mathrm{n}=138) \quad(\mathrm{n}=138) \quad(\mathrm{n}=138) \quad(\mathrm{n}=139) \quad(\mathrm{n}=138)$

3. SPM $.64 * * \quad .42 * * \quad .01 \quad .14$ $(\mathrm{n}=167) \quad(\mathrm{n}=167) \quad(\mathrm{n}=166) \quad(\mathrm{n}=166)$

4. LIT $\begin{array}{lll}.44 * * & -.08 & .27 * *\end{array}$

5. NUM

$$
(\mathrm{n}=167) \quad(\mathrm{n}=166) \quad(\mathrm{n}=166)
$$

5. NUM

$\begin{array}{lll}. & -.14 \quad .10\end{array}$

6. GHQ

$$
(\mathrm{n}=166) \quad(\mathrm{n}=166)
$$

. $-.49 * *$

$$
(\mathrm{n}=166)
$$

\section{RSE}

Note: $*=\mathrm{p}<.05 ; * *=\mathrm{p}<.01$ 
Effects of Occupational Involvement

The 89 participants who completed T1 and T2 questionnaires were allocated to one of three groups based on their occupational status at T2 and on their T1-T2 employment activities. Group UE $(n=38)$ were unemployed at T2 and had not worked between $\mathrm{T} 1$ and T2. Group UE+WK $(n=36)$ were also unemployed at T2 but had had substantial $(>1$ week full-time) T1-T2 paid employment. Group EMP $(n=15)$ were employed at T2. Summary statistics for the three groups are reported in Table 3.

Table 3

Summary Statistics for Study Participants at T1 and T2. Group UE = Participants Unemployed at T2 and no employment T1-T2. Group UE+WK = Participants Unemployed at T2 but Employment T1-T2. Group EMP = Participants Employed at T2.

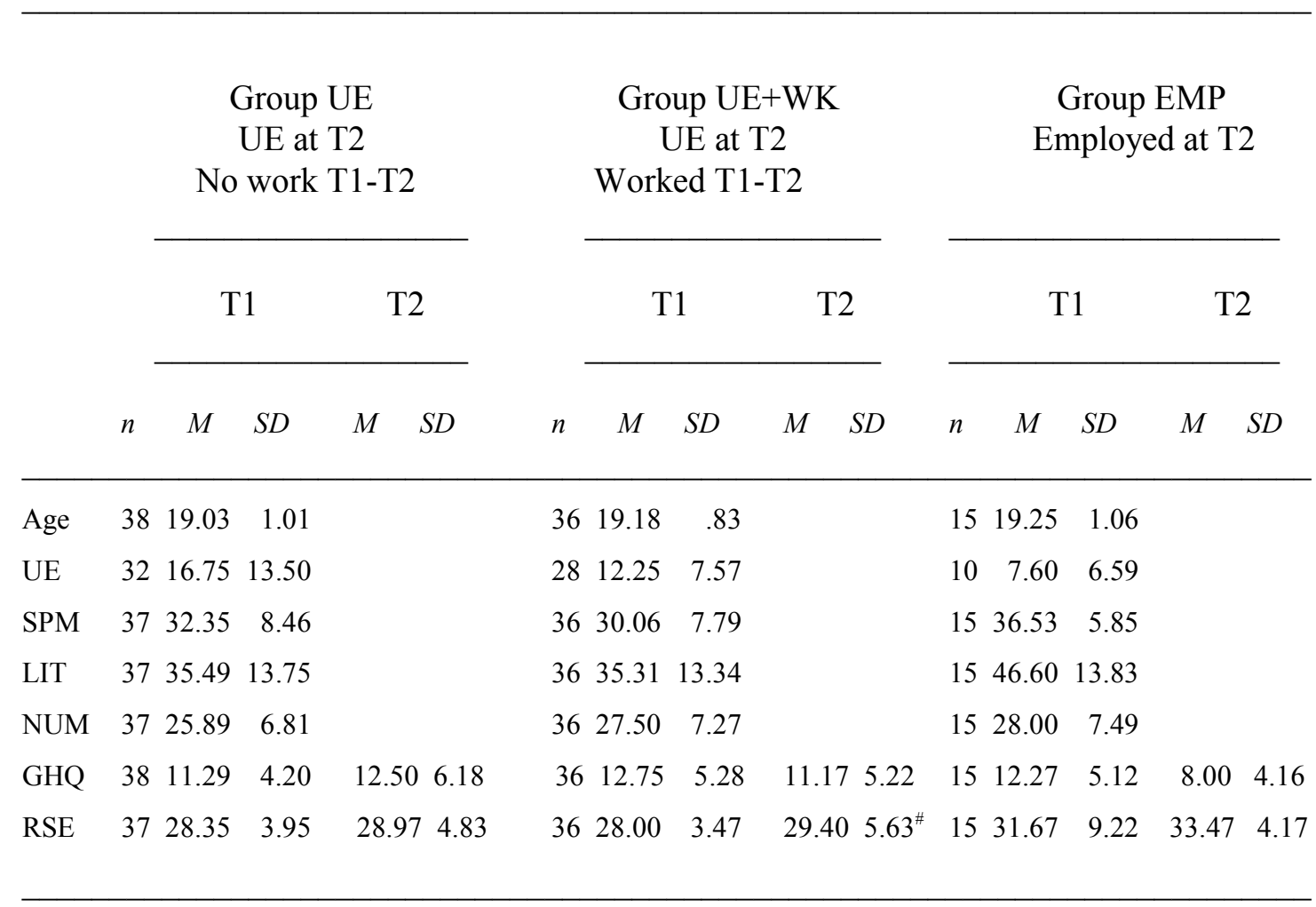

Note: ${ }^{\#}=35$ subjects completed the RSE at T2 
Two repeated measure ANOVA's were conducted to determine the impact of occupational experience on the psychological well-being (GHQ and RSE) of the three groups. Both ANOVA's utilised a between group (Group UE x Group UE+WK x Group EMP) and an across time factor (T1 \& T2). For psychological distress (GHQ), no significant group effect was identified; there was a significant effect for time, $F(1,14)=5.05, p<.05$; and a significant group by time interaction effect, $F(2,28)=4.13, p<.05$. Post hoc analyses (Tukey HSD) indicated no significant differences between the three groups at $\mathrm{T} 1$ on psychological distress; no significant changes across time for Group UE or Group UE+WK; a significant reduction in psychological distress across time for Group EMP; and significant differences between Group EMP and Group UE at T2, and between Group EMP and Group $\mathrm{UE}+\mathrm{WK}$ at T2, (Tukey $R$ Crit $=1.91, M S E=12.99, p<.01)$. Meaningful improvements in psychological distress (GHQ) occurred only for those who were actually employed at T2 (Group EMP). Means for GHQ are presented in Table 3.

For self-esteem (RSE), there was a significant group effect, $F(2,26)=5.49, p<.05$, but no significant time or interaction effect. Means for RSE are presented in Table 3.

\section{Differences Between Groups at T1}

One-way ANOVA and chi-square tests were conducted to determine if there were differences among the three Groups on any of the variables at T1. No differences were identified on the variables of age, sex, education level, numeracy, psychological distress or self-esteem. However, Group EMP was unemployed for significantly fewer months at T1 than Group UE, $F(2,67)=3.21, p<.05$, Tukey, $p<.05$; had a significantly higher general ability level at T1 than Group UE+WK, $F(2,85)=3.67, p<.05$, Tukey, $p<.05$; and had 
higher literacy levels at T1 than both Group UE, $F(2,85)=4.23, p<.05$, Tukey, $p<.05$, and Group UE+WK, Tukey, $p<.05$. Thus, those who were employed at T2 (Group EMP), at T1 had been unemployed for fewer months (than Group UE), had higher general ability levels (than Group UE+WK), and had higher literacy levels (than both Groups UE and $\mathrm{UE}+\mathrm{WK})$.

\section{Prediction of Employment Status at T2}

A multiple discriminant analysis was conducted to determine whether employment status at $\mathrm{T} 2$ could be differentiated by the demographic, individual differences and psychological well-being variables collected at T1. Data from 77 subjects were used in the analysis as 22 subjects had at least one missing discriminant variable (Group UE, $n=31$; Group UE+WK, $n=26$; Group EMP, $n=10$ ). The discriminant analysis yielded two functions, neither of which reached significance $(p>.05$; Wilks's lambda for the first function was .66; for the second, .91).

\section{Discussion}

The three youth groups, based on occupational status at T2, did not differ at $\mathrm{T} 1$ when examined retrospectively on the well-being variable of psychological distress. At T2, only Group EMP had significantly reduced distress levels. Group UE showed a slight (nonsignificant) increase, while Group UE+WK showed a slight (non significant) reduction at T2, placing this group between Group EMP and Group UE. As has been identified in other studies (Winefield \& Tiggemann, 1985; Wanberg, 1995), when individuals move from being unemployed to being employed, their psychological health improves. This was not the 
case for Group UE+WK, although it experienced a (non-significant) reduction in distress. Intuitively it would seem that having some paid work experience would be better psychologically for young people, and that this would lead to reductions in psychological distress. This was not the evidence from this study. Only the group of young people who were actually engaged in paid employment (Group EMP), reported improvements in psychological health. Remaining continuously unemployed is as distressing as unemployment interspersed with short periods of work for young people.

In relation to self-esteem, there was no difference between the three groups at $\mathrm{T} 1$, nor was their any significant effect on this variable in relation to occupational experience. In some studies, leaving school has been found to be a positive experience, even when young people become unemployed (Gurney, 1980; Winefield \& Tiggemann, 1985), and improvements in self-esteem have been reported for school leavers who become unemployed (Winefield \& Tiggemann, 1985). Other studies have reported that for non school leaver groups self-esteem is less dependent on employment status than other psychological health variables (Shamir, 1986; Winefield, Tiggemann, Winefield \& Goldney, 1991). Dooley and Prause (1995) suggested that the best explanation for self-esteem changes in school-leavers in their longitudinal study was that employment in satisfactory jobs led to increases in self-esteem, while becoming unemployed or finding unsatisfactory employment failed to produce self-esteem increases. These authors attributed the lack of self-esteem growth to developmental delay. The evidence from the present study was that moving from being unemployed to being employed, while it did reduce psychological distress, did not bring improvements in self-esteem. Being unemployed and moving into employment, or being unemployed with intermittent work experiences, produced similar results in self-esteem to those who were unemployed and remained unemployed. A developmental delay model does not fit this data. It cannot be ruled out that those employed 
at T2 may themselves be an intermittently employed group who happened to be in work when the measures were completed. Having a paid job may then have temporarily reduced their psychological distress but may have done little to contribute to improvements in ongoing self-esteem. This explanation would be consistent with that provided by Prause and Dooley (1997) who found no differences among groups of underemployed school-leavers on the variable of self-esteem. This account would view both the employed and the intermittently unemployed groups in the present study as underemployed, and imply that both groups are disadvantaged, economically and in other ways, and their occupational status was not contributing to self-esteem growth. A number of other explanations are also possible. It may be that improvements in self-esteem take longer periods in the work force than were possible in this study. It has also been suggested that employment experience may not be essential for the development of self-esteem and that young people develop this aspect of psychological health in other ways (Mean Patterson, 1997).

The consequence of gaining employment was a reduction in psychological distress, but no change in self-esteem. In relation to predisposing factors, neither psychological distress nor self-esteem were different for the three groups at T1 when examined retrospectively. These results are not consistent with other findings that suggested that the less distressed unemployed were more likely to find work (Mean Patterson, 1997; Schaufeli \& Van Yperen, 1992), and earlier findings that those who were more distressed were more likely to experience longer periods of unemployment (Kasl, 1982).

Group EMP and Group UE+WK did not differ on length of unemployment at T1. Group EMP however, had been unemployed for fewer months at T1 than Group UE. Youth with shorter periods of unemployment were more likely to end up in work, or to have paid work experiences, than those youth who were longer unemployed. In other words, longer term unemployed youth were more at risk of being continuously unemployed. On average at T1, 
the number of months unemployed were least for Group EMP, and most for Group UE, with Group UE+WK falling in between. Group UE had experienced longer periods of unemployment than Group EMP (significant) and Group UE+WK (non-significant).

The two unemployed groups at $\mathrm{T} 2$ did not differ at $\mathrm{T} 1$ on levels of general ability. Those employed at T2 did have higher levels of general ability than Group UE+WK. There was no difference on ability between Group EMP and Group UE. Group EMP reported higher levels of general ability than Group UE+WK. There is some evidence here that the unemployed with higher levels of ability were more likely to gain paid work. The employed group had significantly higher levels of general ability than Group UE+WK, but not higher than Group UE. Clearly, there was no simple linear relationship between ability and gaining employment. If this were the case, it would be Group UE who would report the lowest scores. There is some evidence that those with poorer educational levels are more susceptible to unemployment and underemployment (Clogg \& Sullivan, 1983). The present study has provided direct evidence that general ability levels influence obtaining work.

The clearest predisposing factor was literacy. Group EMP had significantly higher literacy levels than both unemployed groups at T1. Clearly, the screening test used (based on word knowledge) is not fully representative of young people's literacy levels. Nevertheless, the evidence from this study is that those with higher levels of literacy were more likely to gain employment. Those with the lower levels were continuously unemployed or intermittently employed. This points to a need for addressing such core skills with unemployed youth, or developing on-the-job strategies to accommodate these deficits.

From this longitudinal study, it is clear that the consequences for young people of gaining employment is a reduction in psychological distress. There was no change on this dimension for those who remained continuously unemployed or who had been intermittently employed. Having exposure to paid employment but being unemployed offered no 
substitute to actually being in a job. For self-esteem, no changes across time were identified for any of the groups. Neither being in employment, nor having paid work experience were able to raise levels of this variable. Further research is needed to tease out the explanation for this, and to extend the research focus to the full variety of occupational statuses. This is especially the case as traditional work experiences are being reduced and other types of employment, such as part-time, temporary and contract work, are on the increase (Leppel \& Clain, 1988).

Neither psychological distress nor self-esteem acted as predisposing factors for occupational status. There was no evidence, for instance, of unemployed youth with poorer psychological health being disproportionately disadvantaged in relation to gaining employment. Ability levels (general and literacy) and length of unemployment were predisposing factors, with those less able and those unemployed longer doing more poorly. What is the evidence for the drift (poor psychological well-being leads to unemployment) and the social causation (unemployment leads to poor psychological health) hypotheses (Dooley, Catalano \& Hough, 1992)? Both the reduction in psychological distress for the employed group, and that there were no predisposing psychological health problems for continued unemployment, add support to the social causation model. As no early base rate for psychological health (e.g., before leaving school) was available, it may well be that the cohort in the present study were subject to drift when compared to their peer cohorts who, for example, entered employment from school. The evidence here does not rule out drift as an explanation in relation to psychological health. It was the case, however, that those with lower levels of ability and literacy continued being unemployed or intermittently unemployed, as would be expected with a drift model. Those less able were less likely to enter the workforce. 


\section{References}

Australian Bureau of Statistics. (1991). Occasional paper: Aboriginal and Torres Strait Islander people in the Australian labour market. Catalogue No 6253.0. Canberra: ABS.

Australian Bureau of Statistics. (1997a). Labour Force Australia. Preliminary Data. Catalogue No 6202.0. Canberra: ABS; July.

Australian Bureau of Statistics. (1997b). 1997 Year Book Australia. No 97. Catalogue No 1301.0. Canberra: AGPS.

Australian Bureau of Statistics. (1997c). Gopher:/gopher.statistics.gov.au, ABS Time Series, Labour Force, Unemployment Rates, Australia-Persons-Total, Table 9I.

Australian Bureau of Statistics. (1997d). Gopher://gopher.statistics.gov.au, ABS Time Series, Labour Force, Unemployment Rates, Australia-Monthly-Region-NSW-Outer Metropolitan Areas, Table 11A.

Australian Bureau of Statistics. (1997e). Aspects of literacy: Assessed skill levels, Australia. Catalogue No 4228.0. Canberra: ABS.

Banks, M. H. \& Ullah, P. (1988). Youth unemployment in the 1980s: Its psychological effects. London: Croom Helm.

Banks, M. H., Clegg, C. W., Jackson, P. R., Kemp, N. J., Stafford, E. M., \& Wall, T. D. (1980). The use of the General Health Questionnaire as an indicator of mental health in occupational studies. Journal of Occupational Psychology, 53, 187-194.

Banks, M. H., Jackson, P. R., Stafford, E. M., \& Warr, P. B. (1980). Young people starting work. Social and Applied Psychology Unit Memo No. 408, University of Sheffield.

Bond, M. J. \& Feather, N. T. (1988). Some correlates of structure and purpose in the use of time. Journal of Personality and Social Psychology, 55, 321-329. 
Broomhall, H. S. \& Winefield, A. H. (1990). A comparison of the affective well-being of young and middle-aged unemployed men matched for length of unemployment. British Journal of Medical Psychology, 63, 43-52.

Creed, P. A. \& Wiener, K. K. (1998). Norms for the Shipley Institute of Living Scale and the Raven's Progressive Matrices for an unemployed population. Manuscript submitted for publication.

de Lemos, M. M. (1989). Standard Progressive Matrices: Australian manual. Hawthorn, Vic.: Australian Council for Educational Research.

de Lemos, M. M. (1990). ACER Word Knowledge Test, Forms E and F: manual. Hawthorn, Vic.: Australian Council for Educational Research.

Dooley, D., Catalano, R. \& Hough, R. (1992). Unemployment and alcohol disorder in 1910 and 1990. Drift versus social causation. Journal of Occupational and Organizational Psychology, 65, 277-290.

Dooley, D. \& Prause, J. (1995). Effect of unemployment on school-leavers' self-esteem. Journal of Occupational and Organizational Psychology, 68, 177-192.

Donovan, A. \& Oddy, M. (1982). Psychological aspects of unemployment: An investigation into the emotional and social adjustment of school leavers. Journal of Adolescence, 5, 15-30.

Feather, N. T. \& Bond, M. J. (1983). Time structure and purposeful activity among employed and unemployed university graduates. Journal of Occupational Psychology, 56, $241-254$

Felvus, J. (1989). Standard Progressive Matrices Test: Norms for a 10-minute administration. Psychological Test Bulletin, 2(1), 20-21.

Goldberg, D. P. (1972). The detection of psychiatric illness by questionnaire. London: Oxford University Press. 
Goldberg, D. P. (1978). Manual of the General Health Questionnaire. Windsor: NFERNelson.

Gurney, R. M. (1980). Does unemployment affect the self-esteem of school-leavers? Australian Journal of Psychology, 32, 175-182.

Jahoda, M., Lazarsfeld, P. F., \& Zeisel, H. (1933). Marienthal: The sociography of an unemployed community. (English Translation, 1971, Chicago: Aldine Atherton).

Jastak, S. \& Wilkinson, G. (1984). Administration manual: Wide Range Achievement Test - Revised. Delaware: Jastak Associates.

Jensen, A. R. (1980). Bias in mental testing. London: Methuen \& Co. Ltd.

Kasl, S. V. (1982). Strategies of research on economic instability and health. Psychological Medicine, 12, 637-649.

Layton, C. (1985). Unemployment and intelligence. Psychological Reports, 57, 653-654.

Layton, C. (1986). Employment, unemployment, and response to the General Health Questionnaire. Psychological Reports, 58, 807-810.

Leppel, K. \& \& Clain, S. (1988). The growth in involuntary part-time employment of men and women. Applied Economics, 20, 1155-1166.

Lynn, R., Hampson, S. \& Magee, M. (1984). Home background, intelligence, personality and education as predictors of unemployment in young people. Personality and Individual Differences, 5(5), 549-557.

Machin, M. A. (1989). The role of general cognitive ability in employment. Discussion Paper: Department Employment Education and Training, Brisbane.

Mean Patterson, L. J. (1997). Long-term unemployment among adolescents: A longitudinal study. Journal of Adolescence, 20, 261-280. 
Morrell, S., Taylor, R., Quine, S., Kerr, C., \& Western, J. (1994). A cohort study of unemployment as a cause of psychological disturbance in Australian youth. Social Science and Medicine, 38(11), 1553-1564.

Patton, W. \& Noller, P. (1984). Unemployment and youth: A longitudinal study. Australian Journal of Psychology, 36, 399-413.

Patton, W. \& Noller, P. (1990). Adolescent self-concept: Effects of being employed, unemployed or returning to school. Australian Journal of psychology, 42, 247-259.

Prause, J. \& Dooley, D. (1997). Effect of underemployment on school-leaver's selfesteem. Journal of Adolescence, 20, 243-260.

Rosenberg, M. (1965). Society and the adolescent self-image. Princeton, N.J.: Princeton University Press.

Rowley, K. \& Feather, N. (1987). The impact of unemployment in relation to age and length of unemployment. Journal of Occupational Psychology, 60, 323-332.

Schaufeli, W. B. (1997). Youth unemployment and mental health: Some Dutch findings. Journal of Adolescence, 20, 281-292.

Schaufeli, W. B. \& Van Yperen, N. W. (1992). Success and failure in the labour market. Journal of Organizational Behaviour, 14, 559-572.

Shamir, B. (1986). Self-esteem and the psychological impact of unemployment in relation to age and length of unemployment. Social Psychology Quarterly, 49, 61-72.

Sheehan, P. (1980). Crisis in abundance. Ringwood: Penguin.

Spearman, C. (1927). The nature of intelligence and the principles of cognition (Second Edition). London: Macmillan \& Co.

Warr, P. B. (1987). Work, unemployment and mental health. Oxford: Clarendon Press.

Wanberg, C. R. (1995). A longitudinal study of the effects of unemployment and quality of re-employment. Journal of Vocational Behavior, 46, 40-54. 
Winefield, A. H. (1995). Unemployment: Its psychological costs. In C. L. Cooper \& I. T. Robertson (Eds.). International Review of Industrial and Organizational Psychology. Chichester: Wiley.

Winefield, A. H. \& Tiggemann, M. (1985). Psychological correlates of employment and unemployment: Effects, predisposing factors and sex differences. Journal of Occupational Psychology, 58, 229-242.

Winefield, A. H. \& Tiggemann, M. (1990). Employment status and psychological wellbeing: A longitudinal study. Journal of Applied Psychology, 75, 455-459.

Winefield, A. H., Tiggemann, M., Winefield, H. R. (1991). The psychological impact of unemployment and unsatisfactory employment in young men and women: Longitudinal and cross-sectional data. British Journal of Psychology, 82, 473-486.

Winefield, A. H., Tiggemann, M., Winefield, H. R., \& Goldney, R. D. (1991). A longitudinal study of the psychological effects of unemployment and unsatisfactory employment on young adults. Journal of Applied Psychology, 76, 424-431.

Winefield, A. H., Tiggemann, M., Winefield, H. R., \& Goldney, R. D. (1993). Growing up with unemployment: A longitudinal study of its psychological impact. London: Routledge.

Zachmann, R. (1986). Reduction of working time as a means to reduce unemployment: A micro-economic perspective. International Labour Review, 125, 163-175. 